\title{
GLOBALIZAÇÃO E PÓS-MODERNO
}

A nous la Libertè, Renè Clair

\section{José Mário Angeli}

\author{
Prof. do Departamento. de Filosofia da UEL.
}

\begin{abstract}
Os conceitos - globalização e pós-moderno - revelam-se, na compreensão sócio-política da realidade. Normalmente eles podem ser identificados no pensar o processo da globalização da economia como sendo o esgotamento do moderno ou, como superação de uma época. Este artigo visa discutir as concepções de globalização como noções de um capitalismo sem sujeito, na qual a pós-modernidade surge como o triunfo do abstrato. Estes conceitos são analisados em confronto com os princípos da "filosofia da práxis", vista como possibilidade de uma subjetividade coletiva, com o objetivo de propor uma caracterização das relações Norte-Sul, estabelecidas pelo capitalismo contemporâneo.
\end{abstract}

Palavras-Chave: Pós-moderno; Globalização; Filosofia da práxis

1 Os conceitos - globalização e pósmoderno - revelam-se, na compreensão sócio-política da realidade. Normalmente eles podem ser identificados no pensar o processo da globalização da economia como sendo o esgotamento do moderno ou como superação de uma época. Identificou-se, nas sociedades industrializadas, uma forma de pensar a sua organização, os seus valores e o comportamento humano como sendo uma ruptura com o moderno, embora, eles sejam diferenciados entre si, porque a globalização se refere ao processo econômico como um todo. O pós-moderno tem sido referido mais como um paradigma de compreensão da contemporaneidade, antes de ser tematizado, isto é, onde a liberdade da subjetividade está colocada como valor último dos seres humanos.

A origem do pós-moderno pode ser identificada, particularmente, após os anos 60 e, fundamentalmente nos movimentos de 68 , pela expressão máxima da liberdade dos homens. Alguns críticos, muito apressadamente, identificaram no pensamento do filósofo alemão Martin Heidegger os fundamentos do pós-moderno. Ele inaugura uma visão de mundo e um modo de conceber o homem que rompe com as determinações históricas das condições materiais de seu tempo e por meio do "imperialismo da linguagem", atribui a esta capacidade de não somente, simbolizar a realidade, mas de produzi-la. (HEIDEGGER, 1990, pp. $27-$ 31). O pós-moderno aparece no cenário filosófico como sendo uma filosofia da linguagem capaz de dar sentido à realidade ou, então, como acentuou Habermas de um "agir comunicativo", pois a comunicação é a dimensão última das sociedades modernas. Assim como, a linguagem tem uma significação determinante para a forma sóciocultural da vida (HABERMAS, 1987, p 11).

Ambos reduzem o mundo das coisas à linguagem e a signos de mera superfície. Assim, o pós-moderno seria uma imposição da linguagem às coisas. Irão identificá-lo como sendo uma "ontologia fraca" (LOSURDO, 1993) e, ao mesmo tempo, imputar a Nietzsche, crítico da moderna sociedade ocidental, uma compreensão muito abstrata do real.

A tentativa de análise neste texto será pensar o pós moderno no contexto da globalização econômica, que incide consequentemente, num mundo de profundas transformações e, por isso, poder pensá-lo como sendo sinônimo do mundo pós-industrial e sobretudo como sendo um paradigma insuficiente de análise do real.

2. A questão que se formula aqui para prosseguir na análise é a seguinte: não será necessário modificar a conceituação vigente da 
globalização? Ao entender que o processo de globalização, em curso na economia, nas comunicações e na cultura, comporta os mais variados entendimentos, desde a sua negação como "algo novo" na face da terra, até sua afirmação como algo irreversível e irresistível; e, ao entender que a realidade é um fluir constante concernente ao seu caráter ontológico, logo, é possível apreender aqueles conceitos por meio de uma visão que seja capaz de se contrapor ao fenômeno empírico que estamos assistindo na contemporaneidade.

A globalização está associada à abertura das fronteiras comerciais, à privatização do Estado, ao acesso tecnológico, aos bens de consumo e até ao cenário de uma nova era na educação e cultura. Mas é, em contraposição, associada à globalização das falências e bancarrotas, da desestruturação produtiva, da flexibilização de direitos dos trabalhadores, do desemprego crescente, do refluxo do movimento sindical e popular e do fim do Estado como indutor de recursos econômicos para o desenvolvimento social e, com prejuízos maiores para os trabalhadores em geral, em favor de uma pequena minoria que dela tem-se beneficiado.

Alguns analistas falam da terceira onda referindo-se à segregação e à exclusão social provocada pelo processo de globalização. Os atuais governos- impulsionados pelos liberais convertidos agora em neoliberais e, pelos ex social-democratas que passaram a defender o fim de políticas distributivas, através da regulação do Estadoimplementam esse processo como sendo a racionalidade suprema. Eles recuperam uma forma "civilizada" entre o Estado e o Mercado, liquidando o Estado em função do livre funcionamento do Mercado, destruindo assim a dialética existente entre eles. Uma relação que já é contraditória em si, pois o funcionamento do Mercado exige um Estado forte para garantir o direito de propriedade, o respeito ao contrato social e à prevalência do processo competitivo.

Uma terceira onda de desigualdade estaria em curso. Ela seria provocada pelo desconhecimento, por milhões de pessoas de uma nova linguagem: $a$ dos computadores. $\mathrm{O}$ monopólio das comunicações, - sua posse sem controle público e a seletividade interessada das suas informações, aumentará o controle político e cultural, já em curso, pela ideologia do mercado em escala planetária (GENRO, 1996). Observação essa relevante, até porque tem-se definido perfis de governantes que mais se adaptam às exigências da mídia.

Paulo Arantes, na SBPC, julho de 96, definia a globalização como sendo um conceito apologético, ambíguo que fala de coisas que não existem. Citava o exemplo do relatório da ONU (Organização das Nações Unidas), sobre o Índice de Desenvolvimento Humano (IDH). Segundo Arantes, as disparidades econômicas entre os países em desenvolvimento e os países industrializados se acentuaram nos últimos anos. O Brasil está em $58^{\circ}$ lugar no $\mathrm{IDH}$, apresentando um desempenho frente a média mundial, abaixo de sua capacidade produtiva. Além disso, muitas das 10 milhões de culturas correm o risco de desaparecerem com a globalização. Para Arantes, a globalização significa uma sociedade interdependente, onde as oportunidades são iguais para todos, sem com isso, levar em consideração as condições de desigualdades dos cidadãos.

O conceito de globalização surgiu na década de 70, quando a academia americana passou a falar de global trade, para orientar as políticas internacionais das empresas americanas. A partir de 1985 quando Gorbachov instaurava a perestroika e glasnot, ele orientava a política Russa, por transparência e abertura do regime soviético, com o objetivo de recuperar a produtividade do sistema socialista em confronto com o capitalista e de restabelecer a paz construindo uma "Europa Comum", uma casa comum. A baixa produtividade do trabalho e a distorção do princípio de justiça social conduzia o desenvolvimento econômico à estagnação (GORBACHEV,1987, p. 19). Tais fatores atuaram na derrocada do socialismo real. .

Particularmente, no final da década de 80 , com o fim do "socialismo real", inaugurou-se uma nova ordem econômica mundial, cuja expressão maior foi a Guerra do Golfo e, que ainda em nossos dias, ela se faz presente. A nova ordem surgiu em nome da ONU, afim de recompor as bases da ordem internacional e das novas relações de forças, logo em seguida ao rompimento do equilíbrio bipolar. $\mathrm{Na}$ realidade a expressão mais adequada, para entender a globalização é a mundialização do capital que se intensificou com o fim do "socialismo real", em 1989.

Marx e Engels oferecem uma das primeiras e mais completas interpretações do capitalismo moderno e global. No Manifesto Comunista, eles afirmam que a burguesia criou um novo internacionalismo através do mercado mundial, ao 
lado da "sujeição das forças da natureza ao homem, do maquinário, da aplicação da química à agricultura e à indústria, da navegação a vapor, das estradas de ferro, do telégrafo, da devastação de continentes inteiros para cultivo, da canalização de rios, do surgimento de populações inteiras como por encanto" (MARX e ENGELS, 1996, p.16). Fê-lo a um alto custo: por meio da violência e da destruição de tradições, da opressão e da redução da avaliação de toda atividade ao frio cálculo do dinheiro e do lucro.

Além disso, afirmavam Marx e Engels: "Essa subversão contínua da produção, esse abalo constante de todo o sistema social, essa agitação permanente e essa falta de segurança distinguem a época burguesa de todas as precedentes. Dissolvemse todas as relações sociais antigas e cristalizadas, com seu cortejo de concepções e de idéias secularmente veneradas: as relações que as substituem tornam-se antiquadas antes mesmo de massificar-se. Tudo que é sólido desmancha no ar, tudo que é sagrado é profanado, e os homens são obrigados finalmente a encarar com seriedade suas condições de existência e suas relações recíprocas" (IDEM, p, 14). Vê-se que a expansão do poder capitalista esteve associada à formação de estruturas políticas dotadas de capacidades organizacionais cada vez mais amplas e complexas para controlar o meio social e político.

Sem sombra de dúvida, a retórica desses autores definem o lado subterrâneo da estética moderna, que tem sua forma no capitalismo. Em "O Capital", Marx toma a mercadoria como uma coisa misteriosa, porque simultaneamente ela incorpora o valor de uso e o valor de troca do trabalhador. $\mathrm{E}$, pelo dinheiro, segundo Marx, os homens dissolvem os seus vínculos com a comunidade tradicional, fazendo desse mesmo dinheiro a verdadeira comunidade. O que é o "fetichismo da mercadoria" senão o mascaramento das relações sociais entre as coisas, forma encontrada pelo dinheiro e a troca no mercado (HARVEY, 1993, p.98). Essa percepção apresenta o problema das relações reais que se encontram prontamente no mercado como elemento globalizador da reprodução da vida social.

3. Gramsci também fala de um capitalismo planetarizado. O seu discurso sobre "o modo de acumulação do capital dos mais monstruosos e doentios" parte da questão meridional, mas vai além do problema da "hegemonia do Norte" sobre o Sul, bem como, da hegemonia da cidade sobre o campo.
O que mais se conta no discurso de Gramsci é que, o discurso da globalização ou seja as supostas relações Norte-Sul, assumem o aspecto de virtude internacional,. Tais relações hoje aparecem como perversamente "neutra" sob a denominação de interdependência, isto é, o sistema hierárquico das nações em um mundo de dominação capitalista (GRAMSCI, p. 2.142-45) que se alastra por todos os países. Em nível de generalidades fica claro que os conceitos geográficos p.ex. Norte - Sul, são sobretudo metáforas, pois eles reenviam a dominação à questão do imperialismo e do colonialismo, outrora sistemas de dominação entre as nações.

A hegemonia do Norte teria sido "normal" e historicamente "benéfica", se o industrialismo tivesse tido a capacidade de ampliar, com um certo ritmo, os seus quadros para incorporar sempre novas zonas economicamente assimiláveis (GRAMSCI, p. 131). Gramsci fazia esse relato em 1930, após a queda da bolsa de Nova York.

Gramsci se pergunta como os homens produzem a riqueza, a vida, as relações sociais e a si mesmo? No seu texto "Americanismo $e$ fordismo", escrito em 1934, é a tentativa de resposta moderna a esta pergunta. Para ele, o americanismo e fordismo significa racionalidade, produtividade e industrialismo. Ele entende que o capitalismo não é somente um modelo, mas uma realidade invasora e penetrante, portadora de um entendimento totalitário no espaço e no tempo.

Segundo Gramsci, americanismo e fordismo, nada mais é que a expressão do poder corporativo da economia como um todo, baseado no "New Deal" (novo tratamento) de Roosevelt, forma encontrada para salvar o capitalismo. Aquilo que Ford, fez sozinho - introduzir o dia de oito horas e cinco dólares como recompensa para os trabalhadores, introduzir um método produtivo, distributivo e de distribuição de mercadorias que organicamente permeia todo o tecido social, e por isso, tende a generalizar-se - ele o fez por meio de um processo de "coerção" e disciplina no processo de trabalho e de "persuasão" dos altos salários para melhorar o padrão de vida do americano. Gramsci chama agora a atenção do envolvimento do Estado no processo produtivo, forma encontrada para salvar o capitalismo da grande depressão.

Gramsci entende ser o novo capitalismo uma realidade lacerada e contraditória, minada no seu interior e no exterior pela sua própria "crise 
orgânica". De tal forma que aquilo que parecia ser moderno nada mais era que uma "modernização conservadora". Esse processo foi descrito como uma "revolução passiva" ao invés de ser o nascimento do novo (GRAMSCI, p. 2.173). A inovação técnica trazida pelo americanismo e fordismo não foi suficiente para retirar o capital da crise generalizada e implementar o desenvolvimento dos homens na década de 20 .

Crise e desenvolvimento capitalístico aparecem intimamente conexos. Há porém uma contradição não formal, substancial que reunifica estes dois termos. $\mathrm{O}$ americanismo $\mathrm{e}$ fordismo se apresentaram como portadores de uma modernidade e de uma conservação. Modernidade porque houve um avanço tecnológico no sistema produtivo pelo método de Ford. Conservação porque eles mantiveram as formas arcaicas da organização social vigente, e até ampliaram-nas pela presença da máquina, colocando muitos trabalhadores à margem da sociedade. Este é o problema central. A partir da época da Revolução Francesa o "moderno" - o Estado moderno descrito por Hegel caracterizou-se por um lado, como sendo um modelo de racionalidade e de progresso e, por outro, como uma bandeira contra o "novo", qual foi, a revolução de 1917 que estava nascendo.

Certamente que os tempos mudaram. Fazendose referência ao modo de produção, a introdução de novas tecnologias no sistema de produção, a questão está em saber distinguir, entre os elementos mais simples e os mais gerais, os que determinam a continuidade daquilo que permanece numa época inteira.

4. Uma dessas características gerais da continuidade, trata do processo de globalização como parte do capitalismo, onde a inovação tecnológica é a sua contra parte. $\mathrm{O}$ paradoxo decorrente desse processo é que a liberalização do trabalho pela técnica se apresenta, como nunca, simultaneamente a liberalização da técnica. $\mathrm{O}$ "americanismo e fordismo', embora tenham se proliferado pelo tecido social, não libertaram o homem de suas condições materiais. Eles criaram um "novo tipo de trabalhador", submisso à maquina.

A inovação tecnológica, como atualização do moderno, não libertou os homens de suas necessidades, mas reduziu simplesmente o trabalhador a "um apêndice da máquina", embora não se tenha conseguido fazer dele um "gorila domesticado", aquele processo "libertador" foi incorporado por um pequeno grupo, antes que, todo um conjunto social. A globalização -mundialização do capital - intensificou-se pela fragmentação do ser humano, através do industrialismo de regiões mais ou menos desenvolvidas, forma de ser do capitalismo.

Uma outra característica da globalização, acentuada por Gramsci, elemento de continuidade, é o processo de imigração das regiões pobres para as ricas. A imigração tem diminuído nos dia de hoje, e mudou somente de qualidade. A existência de um grande contigente desempregado que aflui constantemente aos centros desenvolvidos continua em nossos dias de forma dramática. O movimento de abertura econômica das fronteiras nacionais tem o seu contraponto nas restrições dos direitos dos imigrantes, no avivamento da xenofobia, nos vários tipos de nacionalismos e de conflitos étnicos (BALIBAR 1991, p.57)

Desde que o capital existe (séc.XIV) ele é mundializado. Isto significa que não se tem fronteiras para ele. Desta forma então, se for para falar de economia, ela já foi muito mais aberta do que é hoje. Isto não é novidade, basta olhar para os escritos de Lenin em 1923, depois da primeira guerra mundial quando, ele escreveu "Imperialismo fase superior do capitalismo", a mundialização já era muito evidente.

Uma outra característica da globalização pode ser identificada pelo fato de que poucas empresas são transnacionais. Muitas empresas ditas globais, são na verdade corporações multinacionais baseadas nacionalmente, isto é, elas preservam uma matriz e o controle geograficamente localizado (EXAME, Agosto, 1996, p. 20).

Enfim, uma quarta característica do processo de globalização é o fluxo do capital financeiro e os investimentos diretos. Esse fluxo se restringe aos Estados Unidos, à Europa e ao Japão, onde está cerca de $80 \%$ das corporações mundiais. O que está globalizado é o capital financeiro especulativo, que gira no mundo cerca de 1 trilhão de dólares em 24 horas.

A dialética existente entre o geral e o específico, o mercado e capital, permite entender os elementos de contradição do sistema capitalista. Ao mesmo tempo que o capital se planetariza, o mercado se regionaliza, para se fazer mais forte e mais competitivo. Enquanto ele globaliza um grupo social pequeno, enfraquece um grande grupo social, 
exército de reserva de que falava Marx, capaz de manter o status das elites e de dar fôlego ao mercado.

A origem dessas transformações, para alguns críticos, está na crise de hegemonia do capital americano. Embora os Estados Unidos sejam a maior potência mundial, do ponto de vista militar, de mercado, e das corporações empresariais, a sua economia permanece estagnada há 25 anos. A reorganização das forças produtivas do capitalismo americano se dá no sentido de recuperar a sua hegemonia (MANDEL, 1993). Este fenômeno aparece com uma roupagem de globalização ou como um "novo imperialismo", se pensarmos nas intervenções que estão acontecendo em países periféricos, na maioria patrocinadas pelos Estados Unidos da América (SANTARELLI, 1992, pp7180). Dentro dessa concepção de reconstrução da hegemonia americana Chomsky tece críticas ao processo de globalização como forma de desviar recursos dos países pobres para os países ricos.

A propósito afirmou Chomsky que a "nova ordem imperial" usa seletivamente o liberalismo e gera um mundo de mais pobres e mais lucros. Segundo dados do Banco Mundial "as medidas protecionistas dos países industrializados reduzem as nacionais do Sul do planeta em cerca do dobro da quantidade de ajuda oficialmente concedida à região, ajuda esta que é, em boa parte, uma promoção às exportações dirigida em sua maioria aos setores mais ricos do hemisfério" (CHOMSKY, 1993).

A recuperação da idéia de potência irá estabelecer uma nova geografia biopolítica da vida, nos moldes de uma política neoliberal. Assim, o que nós vemos no Brasil hoje como estabilização de uma política monetária, nada mais é que um deslocamento do capital financeiro, por meio de reformas estruturais (DE SOUZA, 1996), com o objetivo de recuperar a queda tendêncial da taxa de lucro a fim de beneficiar a classe dominante.

A classe dominante brasileira, por ocasião da perda da hegemonia americana, entra em crise e se vê obrigada a buscar saídas para o seu modelo de desenvolvimento. Terminado o ciclo desenvolvimentista, procedeu-se uma coalizão de classe para formar um pacto de dominação que vem dosanos 30 sem fenda até nossos dias. Na tentativa de restabelecer a "dissensão perdida" ela, se recompôs em torno das políticas neoliberais de um governo supostamente democrático. (FIORI, 1996, pp. 72-112).

Neste sentido, é possível perceber a forma como as elites se reapropriaram do Estado Brasileiro. Um Estado que nunca foi público e muito menos democrático popular, processa uma derrocada dos direitos dos trabalhadores sem igual na nossa história; em conseqüência, a esquerda política se vê atraída pelas possibilidades das reformas ampliarem o espaço democrático, até porque o socialismo foi pego pela "terceira onda" isto é, o pós-moderno, agora tudo aquilo que é público é deficitário. A desgraça do capital está na intervenção do público. O Estado Nacional não comporta mais as atribuições do social, até porque ele deixou de ser Estado e passou a ser uma empresa. Por isso, agora será necessário envolver a sociedade para resolver o problema do público. $\mathrm{O}$ Estado de Bem Estar Social da maioria da população brasileira está cada vez mais longe de ser realizado.

Caso concreto é o governo do FHC, que em nome da estabilidade política e da governabilidade, processa um grande ajuste de sua economia, baseado na privatização das empresas geradoras de lucros, na desregulamentação dos direitos dos trabalhadores e na reforma administrativa do Estado, formas de estarem inseridos na globalização. O governo continua atuando através de uma política monetarista de subsídios aos parceiros do sistema financeiro (criação do proer) de financiamento e até de pilhagem, remunerando setores produtivos e improdutivos mais atrasados, pois eles querem a mesma coisa: a manutenção do poder.

Sem pretender ser vidente, no final do governo de FHC, poderemos até ter 20 milhões de pessoas vivendo em idênticas condições de primeiro mundo, mas a grande maioria estará excluída socialmente e dessa forma o governo está postando na "desorganização e desunião histórica da classe subalterna". O governo pretende perpetuar-se no poder, pois agora não tem mais exploração capitalista, até porque a sociedade deve estar inserida na globallização e colaborar com a globalização. Por isso, no imaginário da sociedade, o capitalismo aparece como se fosse sujeito, isto é, abstrai-se as relações de forças que configuram essa realidade. Ser moderno não é pensar os conflitos de clases existes no interior do 
capitalismo, isto nada mais significa do que o triunfo do abstrato.

5. O que é pós-moderno? À parte a polêmica existente em torno do conceito e de suas várias definições, os autores como, Vattino (1989), Lyotard (1990), Baudelaire (1981), Habermas (1987), Rouanet (1992), entendendo-o como comunicação generalizada, isto é, a sociedade dos mass media.

Entretanto, o pós-moderno está ligado a uma concepção da história. História que não pode ser entendida de forma unitária, como pretende o filósofo americano Fukuyama, com seu conceito de "fim da história". Benjamin, definiu a história como discurso unitário. Ela é uma representação do passado construída por grupos e classes dominantes. Segundo, Benjamin, do passado se recebe somente aquilo que parece ser relevante. Ele se pergunta, será que não há, em vozes a que prestamos atenção, um eco de vozes agora silenciadas? (BENJAMIN, 1939, p. 692). Ele deixa claro que não existe uma história única globalizante, capaz de unificar todos os outros, como seria a história que engloba a história da arte, da sexualidade etc.... Neste mesmo sentido pensava Gramsci. Para ele a história é história de classe, determinada pela realidade e pelas organizações coletivas que se contrapõem às fantasmagoria do abstrato (GRAMSCI, p. 1.770).

A idéia de história por sua vez está ligada a de progresso. A crise da idéia de história traz consigo a crise da idéia de progresso, até porque não se pode sustentar que, o caminho que a humanidade está fazendo possa realizar um plano nacional de melhoria das condições sociais, que a conduz à emancipação. Os iluministas, Hegel e Marx, positivistas e historicistas pensavam desta forma que, o sentido da história fosse a realização do homem europeu moderno. Nesse sentido, a crise da idéia de história, crise da idéia de progresso e o fim da modernidade, são apenas acontecimentos determinados por transformações que na maioria delas mudam o comportamento dos homens.

As trasformações impõem sempre sobre os homens uma forte perda de sua "animalidade e espiritualidade". Gramsci já acentuava essas dimensões em 'americanismo e fordismo". Dizia ele, a história do industrialismo foi sempre uma contínua luta contra o elemento "animalidade" do homem. Ela foi um processo ininterrupto, doloroso e sanguinoso, de subjugação dos espíritos, a uma sempre mais complexa e rígida norma de hábitos, sem ter sido tornada uma segunda natureza (GRAMSCI, p,2.161). Comparativamente, as novas transformações, do pós-moderno também estão trazendo uma mudança no modo de ser e de viver dos homens, se pensar sobretudo na cultura do individual. Ele estabelece uma coerção brutal de um grupo social sobre todas as novas forças produtivas da sociedade.

No bojo dessas trasformações está a idéia do livre mercado. Aí se estabelece as determinações reais para os homens buscarem sua emancipação. Neste contexto que, o pensamento pós-moderno mais que uma concepção teórica é um paradigma de análise para se entender a globalização. $O$ que propõe o pós-moderno? Ele propõe os imperativos racionais do mercado, como se fossem por si mesmos capazes de organizar a vida econômica, social e político de uma sociedade.

A introdução das idéias de competição, de eficiência e eficácia características da liberdade do mercado, nada mais são do que um terreno intransponível das relações sociais, políticas e individuais. Essas idéias aparecem fortemente marcada por uma carga ideológica capazes de eliminar as contradições no interior da sociedade.

Marilena Chauí define o pós-moderno, como sendo uma ideologia do Neoliberalismo. Ao afirmar que as antigas idéias da razão, universalidade, consciência, liberdade, sentido da história, luta de classes, justiça, responsabilidade, assim como as distinções entre natureza e cultura, público e privado, ciência e tecnologia, subjetividade e objetividade, perderam a validade, passaram a afirmar como realidades únicas $\mathrm{e}$ últimas a superfície veloz do aparecer social (...) e a vitória individual a qualquer preço $(1995, \mathrm{p}, 84)$.

Seguindo a trajetória de Marx, o pós-moderno pode ser definido como o esvaziamento do concreto da parte do abstrato, isto é, como ocupação, tendencialmente sempre mais integral do valor de uso por parte do valor de troca. Isto é, o capitalismo como entendeu Marx é um processo sem sujeito, se por sujeito se entende a individualidade humana que com as suas intenções e as necessidades pretendem por fim a prática econômica.

Como se sabe, a acumulação é a característica mais importante e fundamental descrita por Marx em nossa sociedade com respeito à pré-capitalista, onde a mais valia é destinada ao consumo das 
classes dominantes. Exatamente, esse processo de acumulação que coloca em movimento o sistema social, onde a quantidade não conhece diferença qualitativa, pois o que interessa e se tolera e a valorização da sua quantidade que, pôr sua vez causa uma tremenda fragmentação do sujeito e dos homens entre si.

Nesse quadro fragmentado acrescenta-se à esfera da produção a terceirização, a flexibilidade dos direitos, a prestação de serviço, usando das mudanças tecnológicas inserida no mundo do trabalho. Para a população sobra somente a exclusão social, paradoxo da globalização e do pósmoderno. Forma de ampliar a acumulação capitalística.

Nesse sentido, não há uma ruptura entre o moderno e pós-moderno. O tempo em que se está vivendo é antes de tudo, uma intensificação do moderno, se da modernidade aceita a definição dada por Marx, isto é, vive-se numa sociedade em que o tempo e o espaço é marcado pelo capital, ou seja, a sociedade da acumulação da riqueza abstrata.

O tempo atual é de fato aquele do amadurecimento do capitalismo, da sua generalização à nível mundial ou, mais especificamente da sua extensão seja horizontal seja vertical. Do ponto de vista horizontal, o capitalismo assimila extensão enormes de diferentes áreas geográfica e econômica de natureza pré-capitalista. Do ponto de vista vertical, há uma compenetração sempre maior começando pelos países de antigas industrializações, entre o processo de valorização e o processo de produção.

Neste sentido sempre há uma maior desapropriação da força de trabalho pelo capital. Por isso, o pós-moderno nada mais é que, o moderno, na sua mais verdadeira realização: a intensificação da abstração real que está no princípio e no fim da sociedade capitalística.

O pós-moderno não pode ser visto como um caleidoscópio, isto é, indivíduos ou coisas que aparecem como figuras de uma mera espacialidade sem forma, sem raiz e sem história. Até porque, no coração da produção tem-se simplesmente o tempo sem o espaço, isto é, absoluta quantidade que não constituindo nenhuma diferença qualitativa, deve somente valorizar e aumentar ela mesma.

6.Em fim, uma última consideração importante neste contexto, trata-se de resgatar o político entendendo-o como movimento de massa capaz de confrontar-se com o individualismo reinante neste processo que estamos vivendo. Porque? Por um lado as forças produtivas estão ativas e atuantes na sociedade contemporânea. O pós-moderno não as eliminou. Por outro lado, essas forças estão submetidas ao domínio global representada na força dos administradores, cada vez mais abstrata e, portanto muitos indivíduos estão cegos aos dispositivos de reprodução da vida.

A globalização e pós-moderno só se constróem com uma democracia política capaz de compor aqueles dispositivos que foram rompidos, o da reassunção social que a multidão fará daquele poder produtivo, isto é, a valorização do trabalho, que o próprio desenvolvimento do sistema capitalista colocou-lhe nas mãos e sobretudo no cérebro dos homens.

Alguns críticos apresentam a tese de superação desse processo, como se a forma de acontentar-se da identidade única, de um possível sujeito alternativo, fundado somente sob a valorização da marginalização da existência e da negatividade da prática na qual a sociedade burguesa condena os grupos subalternos. Para muitos desses críticos devem-se acontentar de uma identidade única negadora das diferenças existenciais do conjunto da sociedade.

O problema é que não se deve acontentar-se simplesmente com a recuperação da subjetividade de um lado, e por outro, as dificuldades da construção do coletivo se esgota sempre mais, consequentemente, isto requer a necessidade de um outro tipo de solidariedade e força. De fato traduzir aquela identidade passiva, espelho e resultado da riqueza abstrata do capital, numa coletividade que viva antes de tudo, da riqueza das diferenças dos indivíduos que a compõe e que a define, é o grande desafio das ciências políticas. Nesse sentido, a "política" é a categoria mais apropriada para pensar a identidade única no interior de uma perspectiva radical de transformação social.

Não se pode pensar a subjetividade numa sociedade abstrata. No entanto, a intensificação da abstração capitalística seja como o esvaziamento das modalidades concretas e qualitativamente ricas da existência - no âmbito da produção e do consumo - sejam por um processo histórico em grau de criar uma subjetividade coletiva de oposição, por sua vez capaz de criar uma grande transformação cultural consistente na confiança do fim do mito da subjetividade individual. 
A "filosofia da práxis" pode ser um instrumento moderno de análise, até porque ela permite compreender a subjetividade capitalista. Um sujeito coletivo nunca foi pressuposto, nunca foi encontrado e nunca ganhou forma com se generaliza nas relações capitalistas da vida. Ele não é posto no horizonte de uma homogeneidade material de base das profundas transformações culturais. Ele não é monístico e indiferente, complexo e diferenciado, cuja igualdade não consiste em impor uma única medida a todos, mas oferecer a todos, iguais condições para realizarem a diferença peculiar de si próprio. Aqui está a radicalidade do projeto de vida e a metodologia política da "filosofia da práxis", capaz de romper com o desafio de pós-moderno.

O dilema colocado pelas novas relações sociais é o seguinte: por um lado tem-se através do pósmoderno uma valorização da "subjetividade burguesa", cada vez mais ativa e, por outro lado, tem-se um "coletivismo proletário" de um marxismo arcaico que não dá mais conta da realidade. Esse dilema não pode ser compreendido por uma "ontologia fraca", incapaz de romper com a fragmentação do mundo contemporâneo, como quer o pós-moderno e como também um marxismo mecânico e economicista.

Opor-se sempre mais à unificante e homologante extensão da produção e da reprodução do capital é vital, como forma de resgatar a complexidade das relações sociais como sendo a única capaz de fazer história e de inđuzir a transformações reais, tendo em vista, a possibilidade de uma subjetividade coletiva. Em última instância, trata-se de uma ação política. A racionalidade dessa ação segue sendo a tessitura dos interesses e o confronto de classe, mas sua necessidade só se realiza historicamente.

A "filosofia da práxis" entende que a ação consciente não é automática. Nem a consciência de classe e nem a revolução estão determinadas pelas condições econômicas do sistema capitalista fatalmente dados, mas sim, quando essa consciência torna operativa. Para tanto, Gramsci conclama a construir um "novo bloco histórico" onde, partindose da sua dinâmica interna, que se constitui por crises políticas e crises orgânicas, se propicia o nascimento de novas hegemonias.

\section{REFERÊNCIAS BIBLIOGRÁFICAS}

ARANTES, P, Comunicação na S.B.P.C, SP, 1996.

BENJAMIN, W,'Uber den Begriff der geschichte". In: Gesammelte Schriften, V.1, T.2. Org. por Rolf

Tiedemann e Hermann Schweppenhauser, Frankfurt a.M, Suhrkamp Verlag, 1974, p. 691-704.

BALIBAR,E e WALLERSTEIN, I, Razza, Nazione,

Classe: le identitá ambigue, . Trad, $O$. Vasile, edizione Associate, Roma, 1991.

CHAỨ, M, "Ética e Universidade", in: Rev.

Universidade e Sociedade, 1995.

CHOMSKY, N, "Novos senhores da humanidade", in: Folha de S. Paulo, 1993.

EXAME, Rev, Ed. Abril Cultural, Agosto 1996.

FIORI, J.L, o Vôo da Coruja. Uma Leitura não

liberal da crise do Estado desenvolvimentista, Ed. RFJ, Rio, 1996.

FIORI, J.L, Em busca do dissenso perdido: Ensaios críticos sobre a festejada crise do Estado, Ed. RFJ, Rio, 1996.

GENRO, T,"Estado, opulência e dominação na terceira onda", in: Rev. Adusp, SP, 1996.

GORBACHEV, M, Perestroika: Novas idéias para o meu país e o mundo. Trad. J. Alexandre, Best Seller, SP, 1987.

GRAMSCI, A, Quaderni del Carcere, Ed. critica dell Instituto Gramsci di Roma, a cura de V.

Gerratana, Einaudi, Torino, 1975.

HABERMAS, J, "A nova intransparência".in: Rev. Cebrap, SP, 1978.

Teoria de la acción comunicativa, Trad. M.

J. Redondo, Ed. Taurus, Madrid, 1987.

HARVEY, D, Condição pós-moderna Trad. Ubirajara

Sobral e Stela Gonçalves, Loyola, SP, 1993.

HEIDEGGER, M, II cammino verso il linguaggio, (a cura di) A. Caracciolo, Mursia, Milano, 1990.

KANITZ, FRARE, COELHO, SOUZA, "Brasil, campeão de desigualdade", in: Rev. Adusp, SP, 1996, pp.6-10.

MANDEL, E, "Neoconservadorismo solapa as liberdades Democráticas" in: Folha de S. Paulo, SP, 1993.

MARX e ENGELS, Manifesto Comunista, Trad. Maria Lucia Como, Ed. Paz e Terra, Rio de Janeiro, 1996.

SANTARELLI, E, Imperialismo, Socialismo, Terzo mondo, Quatrovinti, Urbino, 1992.

SOUZA, H. de, "Quem governa o Brasil" in: Folha de S.Paulo, SP, 1996.

VATTINO, G, A sociedade transparente, trad. Carlos Aboimm de Brito Ed. 70, Lisboa, 1989. 